\title{
A report of three cases of jaundice with thyrotoxicosis
}

\author{
*Akande TO, Balogun WO \\ Department of Medicine, College of Medicine, University of Ibadan, Ibadan, Nigeria
}

\begin{abstract}
Background: Jaundice and hepatic dysfunction have been reported in patients with thyrotoxicosis and could be due to different mechanisms.

Objective: To describe three cases of jaundice occurring in patients with thyrotoxicosis and to illustrate the importance of early institution of thionamides when indicated.

Methods: We present the clinical and laboratory features of three patients presenting within a year with thyrotoxicosis and jaundice and whose clinical conditions improved remarkably following treatment with thionamides. In addition, current literature on the subject is reviewed and summarised.

Results: The three patients presented with goitre and jaundice. None of the patients had received blood products, undergone scarification markings or experienced any previous episode of jaundice. Thyroid function tests in the three patients were consistent with a diagnosis of thyrotoxicosis. Liver function tests showed elevated bilirubin and transaminases. All patients improved remarkably following treatment with thionamides.

Conclusion: It is important to rule out thyrotoxicosis in patients with jaundice of unknown cause and consider early use of thionamides for treatment of the thyrotoxicosis, if confirmed.
\end{abstract}

Key words: Jaundice, thyrotoxicosis, thionamides

African Health Sciences 2013; 13(3): 853 - 856 http://dx.doi.org/10.4314/ahs.v13i3.48

\section{Introduction}

Thyrotoxicosis presenting with jaundice and abnormalities in liver function tests, though not common, has been reported in literature ${ }^{1-3}$. Jaundice in patients with thyrotoxicosis could be due to the thyrotoxicosis itself, could be as a result of drug treatment of the thyrotoxicosis, could be due to conditions associated with autoimmune thyroid disease like autoimmune hepatitis or could be due to unrelated conditions like sepsis or viral hepatitis. We report three patients who presented to our hospital within the same year with thyrotoxicosis, jaundice and hepatic dysfunction.

\section{Case 1}

A 27 year old female presented with a four day history of jaundice, fever, diarrhoea and vomiting. She did not have a past history of jaundice or history of indiscriminate use of injections, multiple sexual partners or blood transfusion.

Physical examination revealed a toxic-looking young woman, wasted, not pale, deeply icteric, febrile and

\begin{tabular}{|l|}
\hline *Corresponding author: \\
Dr Akande Temilola O \\
Department of Medicine, College of Medicine \\
University of Ibadan \\
Ibadan, Nigeria \\
Tel: +2348035175482 \\
E-mail: fumkande@yahoo.com \\
\hline
\end{tabular}

dehydrated. She had a staring gaze with bilateral proptosis. Pulse rate at presentation was 162 beats per minute, regular and blood pressure was 138/ $70 \mathrm{mmHg}$. Abdominal examination revealed tender hepatomegaly $2 \mathrm{~cm}$ below the right costal margin (liver span $13 \mathrm{~cm}$ ). Other systems were normal.

She had a goitre which was smooth, diffuse, and non-tender. An assessment of Graves' disease with probable autoimmune hepatitis was made. Thyroid function tests showed freeT4 >70 (normal 9-20) $\mathrm{pmol} / \mathrm{L}$, T3 3.5 (normal 1.1-3.2)nmol/L,TSH 0.4(normal 0.38-3.8)mIU/L. Hepatitis B surface antigen, anti-HCV and retroviral screening were negative. Serial tests of hepatic function during admission are as shown in table 1 . She was commenced on antibiotics without significant improvement. Later on, propanolol and carbimazole were commenced and she made significant improvement with resolution of the jaundice. She was discharged after two months to be followed up in the endocrine clinic. 


\begin{tabular}{llllll}
\hline & Week 1 & Week 2 & Week 3 & Week 4 & Normal values \\
\hline AST (IU/L) & 70 & 398 & 247 & 224 & $0-37$ \\
ALT (IU/L) & 57 & 425 & 248 & 174 & $0-40$ \\
ALP (IU/L) & 74 & 134 & 99 & 99 & $30-150$ \\
Total protein (mg/dl) & 6.1 & 9.6 & 7.5 & 7.6 & $6.0-8.0$ \\
Albumin (mg/dl) & 2.5 & 4.0 & 3.1 & 3.2 & $3.5-5.0$ \\
Bilirubin total $(\mathrm{mg} / \mathrm{dl})$ & 14.0 & 17.5 & - & 13.9 & $0.2-1.0$ \\
Bilirubin conjugated $(\mathrm{mg} / \mathrm{dl})$ & 11.4 & 9.2 & - & 7.9 & $0-0.4$ \\
\hline
\end{tabular}

AST- aspartate aminotransferase, ALT- alanine aminotransferase, ALP- alkaline phosphatase

\section{Case 2}

A 39 year old female presented with 8 months history of an anterior neck swelling, two weeks history of fever, headache and vomiting and nine days history of jaundice. There were associated palpitations, heat intolerance, warm sweaty palms and progressive weight loss.

She had not received blood products, undergone scarification markings or experienced any previous episode of jaundice. Physical examination revealed an ill-looking young woman, wasted, pale, deeply icteric, febrile, with bilateral proptosis and lid retraction. Pulse rate at presentation was 120 beats per minute, regular and blood pressure of 160/ $60 \mathrm{mmHg}$. She had a goitre measuring 5 by $4 \mathrm{~cm}$ each on the left and right lateral lobes. Other systems were essentially normal. An assessment of thyrotoxicosis likely Graves' disease complicated with jaundice to keep in view sepsis, possibly from gastrointestinal focus was made.
Thyroid function tests showed elevated T3 10.1 (normal 1.0-3.25)nmol/L,T4 251 (normal 65175) nmol/L, TSH<0.1(normal $0.5-6.5) \mathrm{mIU} / \mathrm{L}$ consistent with a diagnosis of thyrotoxicosis. PT/ PTTKwas deranged with an INR of 1.5.

Tests of hepatic functions are as shown in table 2 . Sepsis screen did not yield any positive findings. Thyroid scan showed enlargement of both lobes of the thyroid gland with homogenous echo pattern and no nodules or calcification. Abdominal ultrasonography showed normal liver, biliary tree and gallbladder with no evidence of biliary obstruction. Direct Coomb's test was negative.

She was commenced on antibiotics for a week without resolution of jaundice. Propanolol and carbimazole were then commenced and she made significant improvement with resolution of the jaundice. She was discharged after two months to be followed up in the endocrine clinic. However she defaulted from follow up and has not been seen in the clinic since discharge.

Table 2: Tests of hepatic function during admission

\begin{tabular}{llll}
\hline Tests & $\mathbf{1}^{\text {st }}$ & $\mathbf{2}^{\text {nd }}$ & Normal \\
\hline AST(IU/L) & 176 & 237 & $0-37$ \\
ALT (IU/L) & 114 & 30 & $0-40$ \\
ALP (IU/L) & 142 & 54 & $30-150$ \\
Total protein $(\mathrm{mg} / \mathrm{dl})$ & 7.5 & 6.1 & $6.0-8.0$ \\
Albumin $(\mathrm{mg} / \mathrm{dl})$ & 3.3 & 2.9 & $3.5-5.0$ \\
Bilirubin total $(\mathrm{mg} / \mathrm{dl})$ & 20.7 & 5.7 & $0.2-1.0$ \\
Bilirubin conjugated $(\mathrm{mg} / \mathrm{dl})$ & 15.7 & 4.1 & $0-0.4$ \\
\hline
\end{tabular}

AST- aspartate aminotransferase, ALT- alanine aminotransferase, ALP- alkaline phosphatase 


\section{Case 3}

A 29 year old female presented with 6 months history of anterior neck swelling, 2 weeks history of jaundice and a day history of tremulousness. There was a history of bilateral eye protrusion and weight loss. She had not received blood products, undergone scarification markings or experienced any previous episode of jaundice. Physical examination revealed a toxic-looking young woman, wasted, pale, deeply icteric, febrile, and dehydrated. She had a staring gaze and bilateral proptosis, lid lag and lid retraction. Abdominal examination revealed diffuse tenderness with a firm tender hepatomegaly of $4 \mathrm{~cm}$ below the right costal margin. Liver span was $16 \mathrm{~cm}$. Spleen was tipped and tender. There was no ascites. Neurologic examination revealed a conscious and confused woman with no cranial nerve deficit. Tone and power was normal but reflexes were hyperactive. Cardiovascular and respiratory systems were normal. She had a goitre with right and left lobes measuring 6 by $4 \mathrm{~cm}$ and 5 by $2 \mathrm{~cm}$ respectively, smooth, soft, and non-tender. An assessment of thyroid storm with a background thyrotoxicosis most likely Graves' disease complicated by hepatitis was made.

Thyroid function tests showed elevated freeT3 4.50 (normal $0.92-2.33$ ) pmol/L, free T4 68.73 (normal 9-20) pmol/L, TSH $<0.05$ (normal 0.25-5.0) $\mathrm{mIU} / \mathrm{L}$. PTTK was deranged with an INR of 1.3. Tests of hepatic function showed total bilirubin 4.0 (normal $0.2-1.0) \mathrm{mg} / \mathrm{dl}$, alanine aminotransferase 134(0-40) I.U/L, aspartate aminotransferase 202 (0-37) I.U/L, alkaline phosphatase 103 (30-150) I.U/L, total protein $7.7 \mathrm{mg} / \mathrm{dl}(6.0-8.0) \mathrm{g} / \mathrm{dl}$, albumin $2.1 \mathrm{mg} / \mathrm{dl}(3.5-$ $5.0) \mathrm{g} / \mathrm{dl}$. Hepatic function tests could not be repeated due to financial constraints. She was commenced on aldactone, intranasal oxygen therapy, propanolol, carbimazole and anti-liver failure regimen. She made significant improvement thereafter with disappearance of the jaundice and restlessness. She was discharged after 3 weeks to be followed up in the endocrine clinic. She is currently doing well and thyroid function has improved remarkably.

\section{Discussion}

A complex relationship exists between the thyroid gland and the liver. Thyroid hormones are important for normal hepatic function while the liver is also important in the metabolism of thyroid hormone ${ }^{4}$. This may explain why abnormalities of the thyroid gland can occur in persons with diseases of the liver while various liver abnormalities can also occur in persons with diseases of the thyroid.

We have chosen to report these cases for the following reasons: to show that it is not a very rare occurrence (the three patients presented within a year), to highlight the different ways in which they presented, to raise awareness that hyperthyroidism can be an incidental finding in a patient presenting with jaundice so it should be a consideration and to show that early treatment with thionamides can lead to resolution of the jaundice. To the best of our knowledge, our report is the first to highlight this number of cases of thyrotoxicosis and jaundice presenting within a short period of time in Nigerian patients.

The three patients described all presented with fever and jaundice in addition to features of hyperthyroidism. Like an average clinician, we initially suspected possible septicaemic illness or viral hepatitis which led to management along those lines but none of the patients responded. Improvement was only noticed in each case after commencing carbimazole. This implies that the cause of jaundice was probably the thyrotoxicosis itself.

Liver injury in thyroid disease can be hepatitic or cholestatic ${ }^{5}$. The mechanism underlying the hepatic damage seen in thyrotoxicosis is not clear; however different functional and histological changes have been reported. Hepatic injury from thyrotoxicosis can be induced by ischemic injury. Hyperthyroidism causes an increase in the metabolic rate which then induces a relative decrease in blood flow to certain areas of the liver resulting in hypoxic injury. Thyroid hormones might also have a direct toxic effect on hepatic tissue ${ }^{6}$.

A common reason for co-existence of thyrotoxicosis and jaundice is liver injury induced by several medications, including thionamides which are used in the treatment of hypertoxicosis ${ }^{7-10}$. This was not the case with all our cases as they were not previously diagnosed with thyrotoxicosis and had not received antithyroid medications prior to presentation. Increased levels of transaminases have been seen following initiation of thionamides and this usually occurs within the first few months of treatment ${ }^{10,11}$. Occasionally fulminant hepatic failure occurs. A challenging decision for us was whether to use anti-thyroid agents for these patients knowing that the side effects of the drugs rarely include hepatic 
injury. The estimated incidence of antithyroid associated hepatotoxicosis with both carbimazole and propylthiouracil varies but has been put between 0.1-0.2 percent ${ }^{12}$. Older age and higher dose of these drugs are risk factors for hepatic injury. Hepatic function should therefore be monitored routinely during treatment. Other options that have been successfully used in cases of antithyroid-induced hepatotoxicity include substituting antithyroid agents, use of cholestyramine and radioiodine $9,11,13$.

Other associations between liver dysfunction and thyroid disease include autoimmune hepatitis which is associated with autoimmune thyroid disease 14. The diagnosis of autoimmune hepatitis can only be made after liver biopsy so a liver biopsy is indicated if raised liver enzymes persist after treatment of thyrotoxicosis ${ }^{15}$.

A limitation of our reports is inability to do liver biopsy in any of the patients, partly due to financial constraints, and partly because our patients all responded to treatment of thyrotoxicosis.

\section{Conclusion}

Patients with thyrotoxicosis may have abnormal results of liver function test ranging from mild to severe. Patients presenting with jaundice of unknown cause require close examination and investigations to rule out thyrotoxicosis as the primary cause and prompt institution of thionamides if and when indicated.

\section{References}

1. Hull K, Horenstein R, Naglieri R, Munir K, Ghany $\mathrm{M}$ and Celi FS. Two cases of thyroid storm-associated cholestatic jaundice. Endocr Pract. 2007; 13: 476-80.

2. Hasan MK, Tierney WM and Baker MZ. Severe cholestatic jaundice in hyperthyroidism after treatment with 131-iodine. Am J Med Sci. 2004; 328: 348-50.

3. Owen PJ, Baghomian A, Lazarus JH and Godkin AJ. An unusual cause of jaundice. BMJ. 2007; 335: $773-4$.
4. Huang MJ and Liaw YF. Clinical associations between thyroid and liver diseases. J Gastroenterol Hepatol. 1995; 10: 344-50.

5. Malik $\mathrm{R}$ and Hodgson $\mathrm{H}$. The relationship between the thyroid gland and the liver. QJM. 2002; 95: 559-69.

6. Chawla M and Bal CS. Four cases of coexistent thyrotoxicosis and jaundice: results of radioiodine treatment and a brief review. Thyroid. 2008; 18: 289-92.

7. Fischer MG, Nayer $H R$ and Miller A. Methimazole-induced jaundice. JAMA. 1973; 223: 1028-9.

8. Woeber KA. Methimazole-induced hepatotoxicity. Endocr Pract. 2002; 8: 222-4.

9. Williams KV, Nayak S, Becker D, Reyes J and Burmeister LA. Fifty years of experience with propylthiouracil-associated hepatotoxicity: what have we learned? J Clin Endocrinol Metab. 1997; 82: 1727-33.

10. Vitug AC and Goldman JM. Hepatotoxicity from antithyroid drugs. Horm Res. 1985; 21: 22934.

11. Ekpebegh CO and Levitt NS. A 40-year-old woman who developed jaundice during therapy for thyrotoxicosis. PLoS Med. 2006; 3: e12.

12. Cooper DS. Antithyroid drugs. $N$ Engl J Med. 2005; 352: 905-17.

13. Waseem M, Seshadri KG and Kabadi UM. Successful outcome with methimazole and lithium combination therapy for propylthiouracil-induced hepatotoxicity. Endocr Pract. 1998; 4: 197-200.

14. Inoue K, Okajima T, Tanaka E, et al. A case of Graves' disease associated with autoimmune hepatitis and mixed connective tissue disease. Endocr J. 1999; 46: 173-7.

15. Nobili V, Liaskos C, Luigi G, Guidi R, Francalanci $\mathrm{P}$ and Marcellini M. Autoimmune thyroiditis associated with autoimmune hepatitis. Thyroid. 2005; 15: 1193-5. 